\title{
Read This Page First
}

\section{Learning Materials}

This Study Guide is designed to be used in conjunction with:

Workbook: The Supervision of Office Staff.

\section{Equipment Needed}

You will need an audio-cassette recorder to make a short recording.

\section{Tutor Contact}

The arrangements for tutor contact will depend on the college/learning centre at which you study. This Study Guide contains three Tutor Review Exercises, the first one offering two options. Discuss with your tutor which one you should do.

\section{Prior Knowledge}

No particular assumptions have been made about what knowledge of organisations and offices you are expected to have before starting this Element. However, you will find that Elements 1 and 2 of this Unit provide useful background material. You will also find the Element easier to understand and apply if you are currently working in an office environment (or have recent experience of doing so) and have thought about the ways in which people react to different kinds of supervision or to other people.

\section{Element Overview and Objectives}

These are given on page 4 . Read through them to get an overall view of the Element, and what you will be learning.

\section{Learning Sequence}

The Work Planner chart on page 5 summarises the learning activities for this Element. The times given are approximate and are only a guide to help you plan your work.

When you are ready to start the Element turn to page 6 and follow the directions there. 